\title{
Discovery of Phosphonic Acid-Containing Desaminobenzimidazoles as Fructose 1,6-Bisphosphatase Inhibitors that are Suitable for Oral Delivery via Prodrugs
}

Qun Dang ${ }^{1 *}$, K. Raja Reddy ${ }^{2}$, Srinivas Rao Kasibthatla ${ }^{3}$, Tao Jiang ${ }^{4}$, Frank Taplin ${ }^{5}$, Tony Gibson ${ }^{5}$, Scott C. Potter ${ }^{6}$, Paul D. van Poelje ${ }^{6}$, M. Rami Reddy ${ }^{1}$ and Mark D. Erion ${ }^{1}$

${ }^{1}$ Merck, Rahway, NJ, USA

${ }^{2}$ Mpex Pharmaceuticals, San Diego, CA, USA

${ }^{3} B M S$, Bangalore, India

${ }^{4}$ GNF, San Diego, CA, USA

${ }^{5}$ Takeda, San Diego, CA, USA

${ }^{6}$ Pfizer, Groton, CT, USA

\begin{abstract}
To discover an alternative series of fructose 1,6-bisphosphatase (FBPase) inhibitors that is suitable for oral delivery via prodrugs, the 4-amino group was removed from the initial 4-aminobenzimidazole lead series, since the number of hydrogen bond donors has been suggested to affect oral bioavailability (OBAV). Several desaminobenzimidazoles were discovered as potent inhibitors of FBPase. Compound 2.8 inhibits both human and rat liver FBPase with IC ${ }_{50}$ 's of 0.2 and $2 \mu \mathrm{M}$, respectively. Using compound 2.8 as a tool compound, various prodrugs were explored with several cyclic ester prodrugs showing $>10 \%$ OBAV. The more than 5 -fold improvement of OBAV indicates that removal of the 4-amino group from the 4-aminobenzimidazole scaffold renders the scaffold more suitable for oral delivery via prodrugs. Moreover, OBAV SAR suggests that both molecular weight and lipophilicity (judging by cLogP) are important factors to consider when optimizing for OBAV. ๑2000 Elsevier Science Ltd. All rights reserved.
\end{abstract}

Recently, a series of phosphonic acid-containing 4-aminobenzimidazoles [1] were reported as adenosine-5'monophosphate (AMP) mimics. These phosphonic acids function as inhibitors of fructose 1,6-bisphosphatase (FBPase), and demonstrated in vivo glucose-lowering activities in rodent models of type 2 diabetes mellitus (T2DM). For example, compound 1 (Figure 1) potently inhibits both human and rat liver FBPase, and elicited rapid glucose-lowering in ZDF rats, however intravenous administration was required. [1,2] Efforts to gain oral bioavailability (OBAV) via prodrugs (e.g. bisPOM ester of compound 1 and cyclic ester prodrug 1a) were not successful. Two factors were hypothesized to be responsible for the observed low OBAV: high molecular weight (MW) and the presence of a 4-amino group. To reduce MW significantly, a redesign of the benzimidazole scaffold is needed and may require significant resources and time to complete. On the other hand, investigation of the 4-amino group could be done quickly. Herein, the synthesis and evaluation of a series of phosphonic acid-containing desaminobenzimidazole and their prodrugs as FBPase inhibitors is reported.

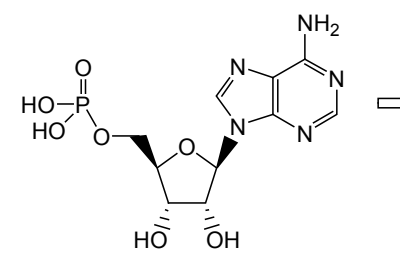

AMP IC ${ }_{50}=1000 \mathrm{nM}$<smiles>CCc1cc(F)c(N)c2nc(-c3ccc(P(=O)(O)O)o3)n(CC(C)C)c12</smiles>

$1 \mathrm{IC}_{50}=90 \mathrm{nM}, \mathrm{OBAV}=2 \%$

$\mathfrak{l}$<smiles>CCc1cc(F)c(N)c2nc(-c3ccc(P4(=O)OCC(COC(C)=O)CO4)o3)n(CC(C)C)c12</smiles>

Figure 1: Benzimidazole 1 as an AMP Mimic.
The desaminobenzimidazole analogs $(1.1-1.19,2.1-2.19,3.1$ 3.19) were readily prepared using our previously reported methods: $\mathrm{FeCl}_{3}-\mathrm{SiO}_{2}$ promoted benzimidazole ring formation followed by TMSBr-mediated removal of phosphonate diesters, [1] as depicted in Scheme 1.

Phosphonate prodrugs (4.1-4.19 and 5.1-5.19) were prepared using either direct alkylation of the phosphonic acid 2.8 with a suitable halide (e.g. for bis[(pivaloyloxy)methyl] (bis(POM) type prodrugs) or dichloridate coupling method via conversion of phosphonic acid 2.8 to its corresponding dichloridate followed by reaction with various alcohols, as shown in Scheme 2.<smiles></smiles>

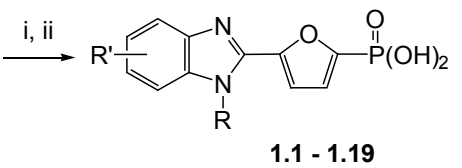

$3 \mathrm{R}$

Scheme 1: Reagents and conditions: i. $\mathrm{FeCl}_{3}-\mathrm{SiO}_{2}$, DMSO; ii. $\mathrm{TMSBr}, \mathrm{CH}_{2} \mathrm{Cl}_{2}$.

*Corresponding author: Qun Dang, Departments of Chemistry and Biochemistry, Metabasis Therapeutics, Inc., 11119 North Torrey Pines Road, La Jolla, CA 92037, USA, E-mail: qun dang@merck.com

Received October 24, 2010; Accepted October 30, 2010; Published November 01, 2010

Citation: Dang Q, Reddy KR, Kasibthatla SR, Jiang T, Taplin F, et al. (2010) Discovery of Phosphonic Acid-Containing Desaminobenzimidazoles as Fructose 1,6-Bisphosphatase Inhibitors that are Suitable for Oral Delivery via Prodrugs. J Diabetes Metab 1:105. doi:10.4172/2155-6156.1000105

Copyright: ( 2010 Dang Q, et al. This is an open-access article distributed under the terms of the Creative Commons Attribution License, which permits unrestricted use, distribution, and reproduction in any medium, provided the original author and source are credited. 
Citation: Dang Q, Reddy KR, Kasibthatla SR, Jiang T, Taplin F, et al. (2010) Discovery of Phosphonic Acid-Containing Desaminobenzimidazoles as Fructose 1,6-Bisphosphatase Inhibitors that are Suitable for Oral Delivery via Prodrugs. J Diabetes Metab 1:105. doi:10.4172/21556156.1000105

Page 2 of 4

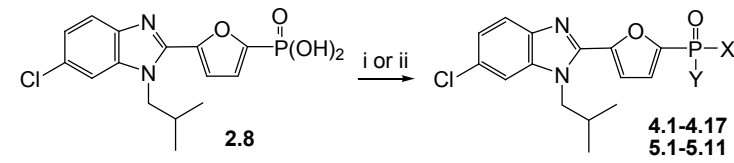

Scheme 2: Reagents and conditions: i. $\mathrm{X}-\mathrm{I}(\mathrm{Y}=\mathrm{X})$, TEA, DMF; ii. $\mathrm{SOCl}_{2} 80^{\circ} \mathrm{C}$; then $\mathrm{X}-\mathrm{H}$ and $\mathrm{YH}, \mathrm{TEA}, \mathrm{CH}_{2} \mathrm{Cl}_{2}$<smiles></smiles>

\begin{tabular}{|l|l|l|l|l|l|}
\hline Cpds & $\mathrm{R}^{4}$ & $\mathrm{R}^{5}$ & $\mathrm{R}^{6}$ & $\mathrm{R}^{7}$ & $\mathrm{IC}_{50}, \mu \mathrm{M}^{\mathrm{a}}$ \\
\hline 1.1 & $\mathrm{H}$ & $\mathrm{H}$ & $\mathrm{H}$ & $\mathrm{H}$ & 12.5 \\
\hline 1.2 & $\mathrm{Me}$ & $\mathrm{H}$ & $\mathrm{H}$ & $\mathrm{H}$ & 4 \\
\hline 1.3 & $\mathrm{H}$ & $\mathrm{Me}$ & $\mathrm{H}$ & $\mathrm{H}$ & 12 \\
\hline 1.4 & $\mathrm{H}$ & $\mathrm{F}$ & $\mathrm{H}$ & $\mathrm{H}$ & 3 \\
\hline 1.5 & $\mathrm{H}$ & $\mathrm{Cl}$ & $\mathrm{H}$ & $\mathrm{H}$ & 5 \\
\hline 1.6 & $\mathrm{H}$ & $\mathrm{Br}$ & $\mathrm{H}$ & $\mathrm{H}$ & 4.7 \\
\hline 1.7 & $\mathrm{H}$ & $\mathrm{CF}_{3}$ & $\mathrm{H}$ & $\mathrm{H}$ & 15 \\
\hline 1.8 & $\mathrm{H}$ & $\mathrm{F}$ & $\mathrm{F}$ & $\mathrm{H}$ & 1.8 \\
\hline 1.9 & $\mathrm{H}$ & $\mathrm{Cl}$ & $\mathrm{Cl}$ & $\mathrm{H}$ & 4.5 \\
\hline 1.10 & $\mathrm{H}$ & $\mathrm{F}$ & $\mathrm{Cl}$ & $\mathrm{H}$ & 3.5 \\
\hline 1.11 & $\mathrm{H}$ & $\mathrm{Me}$ & $\mathrm{Me}$ & $\mathrm{H}$ & 10 \\
\hline 1.12 & $\mathrm{Cl}$ & $\mathrm{H}$ & $\mathrm{Cl}$ & $\mathrm{H}$ & 5.2 \\
\hline 1.13 & $\mathrm{Br}$ & $\mathrm{H}$ & $\mathrm{Br}$ & $\mathrm{H}$ & 5.6 \\
\hline 1.14 & $\mathrm{Br}$ & $\mathrm{H}$ & $\mathrm{F}$ & $\mathrm{H}$ & 2.3 \\
\hline 1.15 & $\mathrm{Me}$ & $\mathrm{Me}$ & $\mathrm{Me}$ & $\mathrm{Me}$ & 0.9 \\
\hline
\end{tabular}

${ }^{\text {alC }}{ }_{50}$, human liver FBPase; ${ }^{b} \mathrm{ND}$, not determined

Table 1: SAR of $\mathrm{N}^{1}-\mathrm{H}$ benzimidazole Phosphonic Acids ${ }^{\mathrm{a}}$.<smiles>[R][R]1c([R])c([R])c2c1nc(-c1ccc(P(=O)(O)O)o1)n2[R]</smiles>

\begin{tabular}{|c|c|c|c|c|c|c|c|}
\hline Cpds & $\mathrm{R}^{1}$ & $\mathrm{R}^{4}$ & $\mathrm{R}^{5}$ & $\mathrm{R}^{6}$ & $\mathrm{R}^{7}$ & $\mathrm{hllC}_{50}{ }^{\mathrm{a}}$ & $\mathrm{rllC}_{50}{ }^{\mathrm{a}}$ \\
\hline 1.1 & $\mathrm{H}$ & $\mathrm{H}$ & $\mathrm{H}$ & $\mathrm{H}$ & $\mathrm{H}$ & 12.5 & $\mathrm{ND}^{\mathrm{c}}$ \\
\hline 2.1 & $\mathrm{Ph}$ & $\mathrm{H}$ & $\mathrm{H}$ & $\mathrm{H}$ & $\mathrm{H}$ & 2 & 20 \\
\hline 2.2 & 4-pyridyl & $\mathrm{H}$ & $\mathrm{H}$ & $\mathrm{H}$ & $\mathrm{H}$ & 5.5 & 20 \\
\hline 2.3 & $\mathrm{iBu}$ & $\mathrm{H}$ & $\mathrm{H}$ & $\mathrm{H}$ & $\mathrm{H}$ & 2 & 12 \\
\hline 2.4 & $\mathrm{Ph}$ & $\mathrm{H}$ & $\mathrm{Cl}$ & $\mathrm{H}$ & $\mathrm{H}$ & 2.5 & 20 \\
\hline 2.5 & $\mathrm{iPr}$ & $\mathrm{H}$ & $\mathrm{Cl}$ & $\mathrm{H}$ & $\mathrm{H}$ & 2.4 & 20 \\
\hline 2.6 & $\mathrm{cPrCH}_{2}-$ & $\mathrm{H}$ & $\mathrm{Cl}$ & $\mathrm{H}$ & $\mathrm{H}$ & 2 & 2 \\
\hline 2.7 & $\mathrm{Ph}$ & $\mathrm{H}$ & $\mathrm{H}$ & $\mathrm{Cl}$ & $\mathrm{H}$ & 0.6 & 2 \\
\hline 2.8 & iBu & $\mathrm{H}$ & $\mathrm{H}$ & $\mathrm{Cl}$ & $\mathrm{H}$ & 0.25 & 2 \\
\hline 2.9 & $\mathrm{CPrCH}_{2}^{-}$ & $\mathrm{H}$ & $\mathrm{H}$ & $\mathrm{Cl}$ & $\mathrm{H}$ & 0.5 & 2 \\
\hline 2.10 & neoPentyl & $\mathrm{H}$ & $\mathrm{H}$ & $\mathrm{Cl}$ & $\mathrm{H}$ & 0.8 & 2 \\
\hline 2.11 & $\mathrm{cPrCH}_{2}-$ & $\mathrm{H}$ & $\mathrm{Cl}$ & $\mathrm{Cl}$ & $\mathrm{H}$ & 3 & 20 \\
\hline 2.12 & $\mathrm{cPrCH}_{2}-$ & $\mathrm{H}$ & $\mathrm{Cl}$ & $F$ & $\mathrm{H}$ & 0.7 & 2 \\
\hline 2.13 & Et & $\mathrm{Me}$ & $\mathrm{Me}$ & $\mathrm{Cl}$ & $\mathrm{H}$ & 0.6 & 17 \\
\hline 2.14 & $\mathrm{Br}\left(\mathrm{CH}_{2}\right)_{4}^{-}$ & $\mathrm{Me}$ & $\mathrm{Me}$ & $\mathrm{Cl}$ & $\mathrm{H}$ & 0.6 & 6 \\
\hline 2.15 & $\mathrm{cPrCH}_{2}-$ & $\mathrm{Me}$ & $\mathrm{Me}$ & $\mathrm{Cl}$ & $\mathrm{H}$ & 0.5 & 6 \\
\hline 2.16 & $\mathrm{cPrCH}_{2}-$ & $\mathrm{Me}$ & $\mathrm{Me}$ & $\mathrm{Me}$ & $\mathrm{Me}$ & 0.2 & 3.5 \\
\hline
\end{tabular}

Table 2: $N^{1}$-SAR of Desaminobenzimidazole Analogs ${ }^{a}$.

To better understand the FBPase inhibitory SAR of the benzimidazole scaffold, a series of $N^{1}$-H benzimidazoles were studied and results are summarized in Table 1.
First, the unsubstituted benzimidazole 1.1 was prepared, which showed an $\mathrm{IC}_{50}$ of $12.5 \mu \mathrm{M}$. Compared to compound 1.1, addition of a methyl group at the 4-position led to 3-fold improvement in potency (compound 1.2, Table 1), while moving the methyl group to the 5-position did not show improvement (compound 1.3, Table 1). Introduction of halo groups at the 5-position also led to compounds (1.4-1.6) with improved potency compared to compound 1.1, but a trifluoromethyl group at the 5-position gave compound 1.7 with similar potency as compound 1.1 , indicating that the trifluoromethyl group may be too big. Three 5,6-dihalo benzimidazole analogs were prepared and compound 1.8 showed significantly improved activity compared to compound 1.1; on the other hand, the 5,6-dimethyl benzimidazole 1.11 showed similar activity as compound 1.1. Compared to compound 1.8, syntheses of 4,6-dihalo benzimidazoles (1.12-1.14) did not improve potency further, while the 4,5,6,7-tetramethyl benzimidazole 1.15 showed slightly improved potency. It is encouraging to see compound 1.8 showing comparable potency as AMP, despite it does not have a $N^{n}$ group, and blocking $N^{n}$-position with a hydrophobic group has been shown to improve FBPase inhibitory potency for the 4-aminobenzimidazole series. [1] Thus, the $N^{n}$-SAR of the desaminobenzimidazole scaffold is investigated, and results are summarized in Table 2 .

As expected, introduction of $N^{1}$-substituents to the parent desaminobenzimidazole 1.1 , produced 2 to 10 -fold improvement in FBPase inhibition activity, entries 1-3, Table 2. Introduction of a chloro group at the 5-position did not improve potency of compounds $2.1-2.3$, on the other hand 6-chlorobenzimidazoles $2.7-2.10$ showed sub-micromolar $\mathrm{IC}_{50}$ with compound 2.8 showing 8 -fold improvement over compound 2.3. Further optimization of compound 2.3 was carried out by introducing multiple substituents on the benzimidazole scaffold and varying the $N^{\mathrm{N}}$-substituents (compounds 2.11 to 2.16 ), but no improvement was obtained over<smiles>[R]c1c([R])c([R])c2c(nc(-c3ccc(P(=O)(O)O)o3)n2CC(C)C)c1[R]</smiles>

\begin{tabular}{|l|l|l|l|l|l|l|}
\hline Cpds & $\mathrm{R}^{4}$ & $\mathrm{R}^{5}$ & $\mathrm{R}^{6}$ & $\mathrm{R}^{7}$ & hllC $_{50}, \mu \mathrm{M}^{\mathrm{a}}$ & $\begin{array}{l}\mathrm{rllC}_{50} \\
\mathrm{MM}^{\mathrm{a}^{\prime}}\end{array}$ \\
\hline $\mathbf{2 . 8}$ & $\mathrm{H}$ & $\mathrm{H}$ & $\mathrm{Cl}$ & $\mathrm{H}$ & 0.25 & 2 \\
\hline $\mathbf{3 . 1}$ & $\mathrm{H}$ & $\mathrm{Cl}$ & $\mathrm{H}$ & $\mathrm{H}$ & 0.6 & 20 \\
\hline $\mathbf{3 . 2}$ & $\mathrm{H}$ & $\mathrm{H}$ & $\mathrm{F}$ & $\mathrm{H}$ & 1 & 2 \\
\hline $\mathbf{3 . 3}$ & $\mathrm{H}$ & $\mathrm{F}$ & $\mathrm{H}$ & $\mathrm{H}$ & 0.8 & 2 \\
\hline $\mathbf{3 . 4}$ & $\mathrm{H}$ & $\mathrm{Br}$ & $\mathrm{H}$ & $\mathrm{H}$ & 2.7 & 20 \\
\hline $\mathbf{3 . 5}$ & $\mathrm{H}$ & $\mathrm{H}$ & $\mathrm{Br}$ & $\mathrm{H}$ & 0.7 & 2 \\
\hline $\mathbf{3 . 6}$ & $\mathrm{HO}$ & $\mathrm{H}$ & $\mathrm{H}$ & $\mathrm{H}$ & 2.5 & 20 \\
\hline $\mathbf{3 . 7}$ & $\mathrm{Me}$ & $\mathrm{H}$ & $\mathrm{H}$ & $\mathrm{H}$ & 1.75 & 20 \\
\hline $\mathbf{3 . 8}$ & $\mathrm{H}$ & $\mathrm{F}$ & $\mathrm{F}$ & $\mathrm{H}$ & 0.45 & 2 \\
\hline $\mathbf{3 . 9}$ & $\mathrm{H}$ & $\mathrm{Cl}$ & $\mathrm{Cl}$ & $\mathrm{H}$ & 2.2 & 2 \\
\hline $\mathbf{3 . 1 0}$ & $\mathrm{H}$ & $\mathrm{Cl}$ & $\mathrm{F}$ & $\mathrm{H}$ & 0.95 & 2 \\
\hline $\mathbf{3 . 1 1}$ & $\mathrm{H}$ & $\mathrm{F}$ & $\mathrm{NH}$ & $\mathrm{Br}$ & 1.2 & 5 \\
\hline $\mathbf{3 . 1 2}$ & $\mathrm{H}$ & $\mathrm{F}$ & $\mathrm{F}$ & $\mathrm{F}$ & 1.55 & 10 \\
\hline $\mathbf{3 . 1 3}$ & $\mathrm{F}$ & $\mathrm{F}$ & $\mathrm{F}$ & $\mathrm{H}$ & 0.5 & 6 \\
\hline $\mathbf{3 . 1 4}$ & $\mathrm{Me}$ & $\mathrm{Me}$ & $\mathrm{Cl}$ & $\mathrm{Br}$ & 0.4 & 2.5 \\
\hline $\mathbf{3 . 1 5}$ & $\mathrm{Br}$ & $\mathrm{Cl}$ & $\mathrm{Me}$ & $\mathrm{Me}$ & 0.75 & 2.7 \\
\hline $\mathbf{3 . 1 6}$ & $\mathrm{Me}$ & $\mathrm{Me}$ & $\mathrm{Me}$ & $\mathrm{Me}$ & 0.25 & 2.25 \\
\hline
\end{tabular}

aHLF, human liver FBPase; RLF, rat liver FBPase; glucose lowering was measured after iv dosing of $10 \mathrm{mg} / \mathrm{kg}$ compounds. ${ }^{b} \mathrm{ND}$, not determined

Table 3: Benzimidazole SAR of compound 2.3 Analogs ${ }^{\mathrm{a}}$. 
Citation: Dang Q, Reddy KR, Kasibthatla SR, Jiang T, Taplin F, et al. (2010) Discovery of Phosphonic Acid-Containing Desaminobenzimidazoles as Fructose 1,6-Bisphosphatase Inhibitors that are Suitable for Oral Delivery via Prodrugs. J Diabetes Metab 1:105. doi:10.4172/21556156.1000105

\begin{tabular}{|c|c|c|c|c|}
\hline Cpds & $\mathrm{R}$ & MW & OBAV, $\%$ & cLogPb \\
\hline 2.8 & $\mathrm{H}$ & 354.7 & 1 & -0.73 \\
\hline 4.1 & $-\left(\mathrm{CH}_{2}\right)_{2} \mathrm{SCOPh}$ & 683.2 & 0 & 8.06 \\
\hline 4.2 & $-\mathrm{CH}_{2} \mathrm{Ph}-(3-\mathrm{Cl}-4-\mathrm{OAc})$ & 663.9 & 0 & 7.89 \\
\hline 4.3 & $-\mathrm{CH}_{2} \mathrm{Ph}-(3,4-\mathrm{di}-\mathrm{OAc})$ & 767.1 & 1 & 3.61 \\
\hline 4.4 & $-\mathrm{CH}_{2} \mathrm{Ph}-(3-\mathrm{Me}-4-\mathrm{OAc})$ & 679.1 & 1 & 6.56 \\
\hline 4.5 & $-\mathrm{CH}_{2} \mathrm{Ph}-(3-\mathrm{OMe}-4-\mathrm{OAc})$ & 711.1 & 1 & 5.29 \\
\hline 4.6 & $-\mathrm{CH}_{2} \mathrm{Ph}-(3-\mathrm{Br}-4-\mathrm{OMe})$ & 752.8 & 1 & 7.94 \\
\hline 4.7 & $-\mathrm{CH}_{2} \mathrm{OCOOPh}-(2-\mathrm{Me})$ & 683.0 & 1 & 7.17 \\
\hline 4.8 & $-\mathrm{CH}_{2} \mathrm{OCOBu}-\mathrm{t}$ & 583.0 & 0 & 6.07 \\
\hline 4.9 & $-\mathrm{CH}_{2} \mathrm{OCOPr}-\mathrm{i}$ & 555.0 & 1 & 5.37 \\
\hline 4.10 & $-\mathrm{CH}_{2} \mathrm{OCOPh}$ & 623.0 & 1 & 7.65 \\
\hline 4.11 & $-\mathrm{CH}_{2} \mathrm{SCOPh}$ & 655.1 & 1 & 7.73 \\
\hline 4.12 & $-\mathrm{CH}_{2} \mathrm{OCOPh}-(4-\mathrm{F})$ & 659.0 & 0 & 7.82 \\
\hline 4.13 & $-\mathrm{CH}_{2} \mathrm{OCO}$ (3-furyl) & 602.9 & 1 & 5.81 \\
\hline 4.14 & $-\mathrm{CH}_{2} \mathrm{OCO}$ (2-furyl) & 602.9 & 1 & 5.24 \\
\hline 4.15 & - $\mathrm{CH}_{2} \mathrm{OCO}$ (2-thienyl) & 635.0 & 1 & 6.86 \\
\hline 4.16 & - $\mathrm{CH}_{2} \mathrm{OCO}$ [3-pyridyl-(6-Cl)] & 693.9 & 1 & 6.31 \\
\hline 4.17 & $-\mathrm{CH}_{2} \mathrm{OCO}$ [3-pyridyl-(6-Br)] & 782.8 & 0 & 6.59 \\
\hline
\end{tabular}

Table 4: OBAV SAR of Phosphonate 2.8 Diester Prodrugsa.

\begin{tabular}{|l|l|l|l|l|l|}
\hline Cpds & $\mathrm{X}$ & $\mathrm{Y}$ & $\mathrm{MW}$ & $\mathrm{OBAV}, \%$ & cLogP \\
\hline $\mathbf{2 . 8}$ & $\mathrm{NA}$ & $\mathrm{NA}$ & 354.7 & 1 & -0.73 \\
\hline $\mathbf{5 . 1}$ & $\mathrm{Ph}$ & $\mathrm{H}$ & 470.9 & 0 & 5.25 \\
\hline $\mathbf{5 . 2}$ & 4 -F-Ph & $\mathrm{H}$ & 488.9 & 2 & 5.30 \\
\hline $\mathbf{5 . 3}$ & $3-\mathrm{Br}-4-\mathrm{MeO}-\mathrm{Ph}$ & $\mathrm{H}$ & 579.8 & 0 & 5.74 \\
\hline $\mathbf{5 . 4}$ & 3 -furyl & $\mathrm{H}$ & 460.8 & 0 & 4.41 \\
\hline $\mathbf{5 . 5}$ & 4 -pyridyl & $\mathrm{H}$ & 471.9 & 12 & 3.76 \\
\hline $\mathbf{5 . 6}$ & 2 -pyridyl & $\mathrm{H}$ & 471.9 & 6 & 3.76 \\
\hline $\mathbf{5 . 7}$ & $\mathrm{H}$ & $\mathrm{CH}_{2} \mathrm{OH}$ & 424.8 & 11 & 2.67 \\
\hline $\mathbf{5 . 8}$ & $\mathrm{H}$ & $\mathrm{CH}_{2} \mathrm{OAc}$ & 466.9 & 10 & 3.57 \\
\hline $\mathbf{5 . 9}$ & $\mathrm{H}$ & $\mathrm{CH}_{2} \mathrm{OCO} \mathrm{Me}$ & 482.9 & 14 & 3.54 \\
\hline $\mathbf{5 . 1 0}$ & $\mathrm{H}$ & $\mathrm{CH}_{2} \mathrm{~N} 3$ & 449.8 & 13 & 3.58 \\
\hline $\mathbf{5 . 1 1}$ & $\mathrm{H}$ & $\mathrm{CH}_{2} \mathrm{NH} 2$ & 423.8 & 4 & 2.72 \\
\hline
\end{tabular}

${ }^{2} \mathrm{OBAV}$ determined by measuring urinary excretion of 2.8 following oral administration of the prodrug vs i.v. administration of 2.8; ${ }^{b} \mathrm{ADME}$ Boxes version 3.5 (Pharma Algorithm, Toronto, Canada) was used

Table 5: OBAV SAR of Phosphonate 2.8 Cyclic Ester Prodrugs ${ }^{a}$.

compound 2.8. It is noteworthy that compound 2.8 is only 3 -fold less potent than compound 1 , but it does not have a 4 -amino group. To fine-tune compound 2.8 , attention was turned to the benzimidazole SAR established for the 4-aminobenzimidazole scaffold, which suggested smaller groups such as halo, $\mathrm{Me}, \mathrm{OH}$ are preferred. Thus, the benzimidazole SAR of compound 2.8 was investigated using isobutyl as the $N^{1}$-group, and results are summarized in Table 3.

The SAR presented in Table 3 indicates that even though halo and small alkyl groups were keys to improve potency for the 4-aminobenzimidazole scaffold, no clear potency enhancement was achieved by the syntheses of compounds 3.1 to 3.16. For example, a fluoro group at the 5-position was key for the potent FBPase inhibitory activity of benzimidazole 1 , but none of the 5-fluorodesaminobenzimidazoles 3.3, 3.8, and 3.11-3.13 showed higher potency than compound 2.8. Therefore, desaminobenzimidazole 2.8 was selected as the tool compound to test whether elimination of the 4-amino group from the initial benzimidazole scaffold will help to improve OBAV via prodrugs. Various phosphonate diester prodrugs were prepared and evaluated OBAV in a rat urinary secretion model, [6] and results are summarized in Table 4.

Most of the commonly reported phosphonate diester prodrugs such as SATE diester (compound 4.1), dibenzyl esters (compounds 4.2-4.4.6), bis(alkoxycarbonyloxymethyl) esters (compound 4.7) and acyloxymethyl esters (compounds 4.8 - 4.17) were prepared, but none showed any apparent improvement in OBAV over the parent phosphonic acid 2.8 itself. Among the acyloxymethyl diesters tested, lower MW prodrugs 4.8 and 4.9 did not fair any better versus higher MW prodrugs 4.16 and 4.17. No correlation between OBAV and cLogP was observed either. It is noted that high MW (555-783) is common to all of these prodrugs, which may be reason for the observed low OBAV. [7] Thus, the smaller cyclic ester prodrug approaches were investigated for compound 2.8 , which should produce prodrugs with relatively lower MW and results are summarized in Table 5.

Cyclic 1,3-propyl phosphonate esters were discovered by Metabasis and proved to be an useful prodrug approach (HepDirect prodrugs) to deliver phosphonic acids orally [8]. Six Hepdirect prodrugs of compound 2.8 were prepared with five out of the six prodrugs having $\mathrm{MW}<500$. It is very encouraging to see that two prodrugs (compounds 5.5 and 5.6) showed improved OBAV compared to compound 2.8, Table 5 . Given that all six prodrugs have similar MW, but prodrugs 5.5 and 5.6 are less lipophilic compared to prodrugs 5.1-5.4 (judging by cLogP), the higher OBAV observed for compounds 5.5 and 5.6 is likely to due to their decreased lipophilicity (which in turn should increase solubility). Encouraged by compounds 5.5 and 5.6, five other cyclic esters of compound 2.8 were prepared as $5.7-5.11$ and four out of the five cyclic esters with various substituents at the 4-position of the 1-phospha-2,6-oxa-cyclohexane ring showed greater than $10 \% \mathrm{OBAV}$. It is noted that all four prodrugs (5.7 - 5.10) have lower cLogP than prodrugs $5.1-5.4$. Moreover, in a head to head comparison of the same type of prodrugs, compound 5.8 showed 5-fold higher OBAV compared to compound 1a, which suggests that the 4-amino group in compound 1 is indeed a limiting factor for the observed low OBAV of compound 1 prodrugs.

In summary, a series of desaminobenzimidazole FBPase inhibitors were discovered as a result of extensive SAR exploration of the benzimidazole scaffold. Compound 2.8 , which lacks an amino group on the benzimidazole nucleus, inhibits both human and rat liver FBPase with $\mathrm{IC}_{50}$ 's of 0.2 and $2 \mu \mathrm{M}$, respectively. Using compound 2.8 as a tool compound, various prodrugs were explored with several cyclic ester prodrugs showing $>10 \%$ OBAV. The more than 5 -fold improvement in OBAV over the parent phosphonic acid 2.8 by several prodrugs indicates that removal of the 4-amino group from the benzimidazole scaffold renders the benzimidazole scaffold more suitable for oral delivery via prodrugs. Moreover, prodrug OBAV SAR suggests that both MW and lipophilicity (judging by cLogP) are important factors to consider when optimizing for OBAV.

\section{References}

1. Dang Q, Kasibhatla SR, Xiao W, Liu Y, Dare J, et al. (2010) Fructose1,6-bisphosphatase Inhibitors. 2. Design, synthesis and structure-activity 
Citation: Dang Q, Reddy KR, Kasibthatla SR, Jiang T, Taplin F, et al. (2010) Discovery of Phosphonic Acid-Containing Desaminobenzimidazoles as Fructose 1,6-Bisphosphatase Inhibitors that are Suitable for Oral Delivery via Prodrugs. J Diabetes Metab 1:105. doi:10.4172/21556156.1000105

Page 4 of 4

relationship of a series of phosphonic acid containing benzimidazoles that function as 5'-adenosinemonophosphate (AMP) mimics. J Med Chem 53: 441451.

2. van Poelje PD, Dang Q, Erion MD (2007) Discovery of fructose-1,6bisphosphatase inhibitors for the treatment of type 2 diabetes. Curr Opin Drug Discov Devel 4: 103-108.

3. Erion MD, van Poelje PD, Dang Q, Kasibhatla SR, Potter SC, et al. (2005) MB06322 (CS-917): A potent and selective inhibitor of fructose 1,6-bisphosphatase for controlling gluconeogenesis in type 2 diabetes. Proc Natl Acad Sci U S A 102: 7970-7975.

4. Erion MD, Dang Q, Reddy MR, Kasibhatla SR, Huang J, et al. (2007) Structureguided design of AMP mimics that inhibit fructose-1,6-bisphosphatase with high affinity and specificity. J Am Chem Soc 129: 15480-15490.

5. Dang Q, Kasibhatla SR, Reddy KR, Jiang T, Reddy MR, et al. (2007) Simple and Effective 3D Recognition of Domoic Acid Using a Molecularly Imprinted
Polymer [J. Am. Chem. Soc. 2007, 129, 13626-13632]. J Am Chem Soc 129 15491-15502.

6. (a) Dang Q, Kasibhatla SR, Jiang T, Fan K, Liu Y, et al. (2008) Discovery of phosphonic diamide prodrugs and their use for the oral delivery of a series of fructose 1,6-bisphosphatase inhibitors. J Med Chem 51: 4331-4339.

(b) Reddy MR, Erion MD (2001) Calculation of relative binding free energy differences for fructose 1,6-bisphosphatase inhibitors using the thermodynamic cycle perturbation approach. J Am Chem Soc 123: 6246.

7. Lipinski CA, Lombardo F, Dominy BW, Feeney PJ (1997) Experimental and computational approaches to estimate solubility and permeability in drug discovery and development settings. Avd Drug Delivery Rev 46: 3-26.

8. Erion MD, Reddy KR, Boyer SH, Matelich MC, Gomez-Galeno J, et al. (2004) Design, synthesis, and characterization of a series of cytochrome $\mathrm{P}(450)$ $3 \mathrm{~A}$-activated prodrugs (HepDirect prodrugs) useful for targeting phosph(on) ate-based drugs to the liver. J Am Chem Soc 126: 5154-5163. 